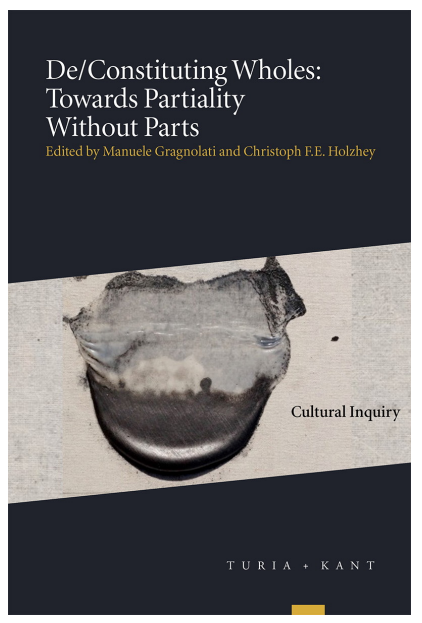

De/Constituting Wholes: Towards Partiality Without Parts, ed. by Christoph F. E. Holzhey and Manuele Gragnolati, Cultural Inquiry, 11 (Vienna: Turia + Kant, 2017), pp. 151-76

\author{
ROBERT MEUNIER \\ VALENTINE REYNAUD
}

\section{The Innate Plasticity of Bodies} and Minds

\author{
Integrating Models of Genetic Determination and \\ Environmental Formation
}

CITE AS:

Robert Meunier and Valentine Reynaud, 'The Innate Plasticity of Bodies and Minds: Integrating Models of Genetic Determination and Environmental Formation', in De/Constituting Wholes: Towards Partiality Without Parts, ed. by Christoph F. E. Holzhey and Manuele Gragnolati, Cultural Inquiry, 11 (Vienna: Turia + Kant, 2017), pp. 151-76 <https://doi.org/10.37050/ci-11_08>

RIGHTS STATEMENT:

(C) by the author(s)
This version is licensed under a Creative Commons Attribution-
ShareAlike 4.0 International License. 


\title{
THE INNATE PLASTICITY OF BODIES AND MINDS
}

\author{
Integrating Models of Genetic Determination \\ and Environmental Formation
}

Robert Meunier and Valentine Reynaud ${ }^{*}$

\section{INTRODUCTION}

\section{Reverberations}

In recent years, concepts of plasticity and epigenetics have gained currency in different areas of the life sciences, from evolutionary theory via developmental biology and neurobiology to medicine. The theoretical considerations attached to these terms and the experimental exploration of the phenomena they refer to are seen as challenging gene-centred, reductionist approaches in biology and medicine and are thought to provide better-suited explanations for evolutionary change and novelty, ontogenetic development, the functioning of the brain, and disease expression. It is their seemingly nondeterministic implications, or at least their acknowledgement of a multiplicity of causes, including environmental factors, that gave these concepts credibility outside of biology as well, in fields such as sociology, cultural studies, and new feminist materialism. ${ }^{1}$ At least with respect to epigenetics, a veritable hype and an expanding set of expectations can be diagnosed, which has not only affected the life sciences, social sciences, and the humanities but also begun to shape the imagination of the public at large, mainly through considerable media coverage. ${ }^{2}$

Such biological concepts reverberate outside of their scientific realms, changing views on the body, the self, and their relation to the realms of agency, morality, and identity. On the other hand, as has happened to other developments in biology before, scientific results articulated in terms of epigenetics and plasticity are shaped by constraints and expectations found in society. In this case, it is the increased individualization of health concerns and the desire to control and improve the body in the absence of manifest pathological states, but also the

Both authors contributed equally to this article and appear in alphabetical order.

We would like to thank the editors for their helpful suggestions. 
regulations of stem cell science and other factors, that enable and shape research, in particular in neurobiology and biomedicine. The life sciences and society are thus entangled in a co-productive relationship, as scholars in science and technology studies (STS) have described on many occasions. ${ }^{3}$

We think that these larger questions about the relation between the respective sciences and culture/society motivate a closer exploration of the issues within the life and cognitive sciences. That is why in this article we will focus neither on the interpretation of biological findings for a broader cultural understanding of the body or the self, nor on the social conditions for the research that brings them about. Instead, we wish to ask primarily how plasticity and epigenetics relate to some notions in biology that they are often taken to oppose, such as genetic determination, genetic programme, and innateness.

\section{Conflict or Complementarity?}

Although the critique of genetic determinism is as old as the notion of genes playing a somehow more prominent role in heredity, development, and evolution than other factors, a gene-centred view of biology prevails, and it often takes the form of strong genetic determinism. This has many reasons, some epistemic, some practical, and some political. On the epistemic side, genes and the associated molecular mechanisms provide simple explanations in terms of bottom-up causal pathways within a framework of a clear-cut hierarchy of biological organization from molecules to ecosystems; in contrast, the environment, with its multiplicity of causal aspects on various layers of organization, seems particularly hard to conceptualize in a coherent manner. Based on that epistemic presupposition, pragmatic and political agendas in contexts from agriculture to health and disease are often characterized by a rhetoric of control that requires the possibility of naming the causes; these agendas in turn favour the kind of research that supports such causal narratives. The notion of genetic risk associated with certain diseases is an obvious example. ${ }^{4}$

Criticism of gene-centred views or genetic determinism has been elaborated from many perspectives, including biology, psychology, linguistics, philosophy, history, STS, and feminism, among others. Lately, much of the most productive criticism, offering conceptual alternatives, has accumulated around the terms 'plasticity' and 'epigenetics'. These 
two terms have different histories, different fields of application, and, for sure, quite distinct meanings. Nevertheless, they both point to the significance of the environment in development. While epigenetics emphasizes the way the internal and external environment of cells intervenes on a molecular level, in particular by regulating the expression of genes, plasticity points to the product of environmental variation by referring to the phenotypic variation (i.e., variation in any property of an individual - morphological or mental - that is considered from a biological point of view) induced by environmental changes. With respect to epigenetics, a terminological shift occurred. Today, epigenetics denotes the molecular mechanisms by which a cell acquires a structural or functional state and by which this state is transmitted in a cell lineage, also across generations. These mechanisms include those that mediate environmental factors and are thus underlying plasticity. (This more narrow notion will be discussed below in section II.) The term 'epigenetics' was introduced, however, by Conrad Waddington in the 1940s in a much broader sense as 'the branch of biology which studies the causal interactions between genes and their products, which bring the phenotype into being'. 5 This meaning prevails especially in the debates on innateness that will be the subject of section III.

In the following section of this article, we characterize the biological content of the concepts of plasticity and epigenetics and discuss some of the issues that they are supposed to reform by offering alternatives with respect to standard gene-centred views of evolution and development. In section III, we approach the theme through the lens of innateness ascriptions, mainly in cognitive science. In both cases, we arrive at the conclusion that while notions of plasticity and epigenetics seem to oppose genetic determinism or innateness by pointing to the role of environment, the plasticity of morphological and cognitive development requires not a homogeneous material that is formed by the environment but rather a number of specific resources and mechanisms in order to occur. From this perspective, epigenetic regulation appears to mediate between variable environmental inputs and relatively stable genetic material. The plastic response to environmental factors is enabled and articulated in developmental routines. The latter are activated by epigenetic mechanisms and exhibit stability provided by the specificity embodied in genetic material and basic capacities to learn, which can be characterized as innate. 


\section{GENE-CENTRISM, PHENOTYPIC PLASTICITY, AND EPIGENETICS IN BIOLOGY}

\section{Gene-Centred Biology}

To understand why the theories clustering around the notions of epigenetics and plasticity are hailed as revolutionary or as facilitating new unified views in neuroscience and evolutionary biology, it is important to understand what they revolt against, or from what they were excluded before. The target for the rhetoric of overcoming, which is prevalent in these research fields and even more so in other discourses drawing on such research, is represented by gene-centred views of evolution and development in biology. The 'received view' of evolutionary theory was largely developed in the 1930s and is often referred to as the modern synthesis of genetics and Darwinian evolutionary theory; it conceives of evolution as natural selection of gradual, hereditary variation, where only the genetic material is considered to be inherited. ${ }^{6}$ In contrast, biologists today emphasize the role of plasticity, epigenetics, and niche construction in the process of evolution (a trend sometimes referred to as 'extended synthesis'). . What is challenged by these new views with respect to development is the deterministic notion of the genome as a programme or blueprint of an organism. ${ }^{8}$ Plasticity and epigenetics in this context give space to account for the role of environment in development.

In line with the received view of evolution, Hull et al. have provided a general account of selection that applies also to somatic selection processes; they define selection as 'repeated cycles of replication, variation, and environmental interaction so structured that environmental interaction causes replication to be differential'.' According to this account 'selection is two processes, not one'. ${ }^{10}$ The two processes are replication, which can involve variation, and environmental interaction, which refers to the interactions of an organism with its organic and inorganic environments insofar as they influence the reproductive success of the organism. The formulation of selection as entailing two processes is meant to dissolve misunderstandings concerning the units of selection. According to Hull et al, genes are the units of replication and organisms are the units of interaction. Thus they are both units of selection.

Variation is thus located on the level of the gene and depicted as due to occasional random events - mutation and recombination - 
that interfere with the developmental processes and provide the resources for change. This genetic variation can cause phenotypic variation, which in turn affects the environmental interaction of individual organisms, leading to more or less reproductive success compared with individuals of the same species that do not exhibit this genetic variation, and thus to an increase or decrease of frequency within a population of this genetic variation and the phenotypic variation it brings about. As Lindley Darden and Joseph A. Cain have pointed out, environmental interaction is the actual step of selection. ${ }^{11}$ Phenotypic variation leads to differential reproduction in that the organisms interact with the environment and some benefit due to the phenotypic variation they exhibit. The concept of an adaptation encapsulates the idea that phenotypic traits are selected for beneficial interaction with the environment. Adaptation refers to an environmental interaction that is already fixed due to its beneficial effect, but new phenotypic variation might induce many new causal interactions for selection to operate on. As Darden and Cain have pointed out, discussions on the nature of selection mainly focuses 'on the effects of selection, namely differential survival and reproduction'. ${ }^{12}$ The actual causal nature of the interaction is not taken into account, and accordingly, there is no account of how new phenotypic variation comes about, is shaped by the environment, or becomes fixed in individual development. The only question that is answered in the received view is how the distribution of a phenotypic variation becomes fixed in a population. Furthermore, as will be discussed below, the conventional view cannot explain novelty in evolution.

A gene-centred perspective on development is inscribed in both the question of differential gene expression and the suggestion of a genetic programme as its solution. If genes are the primary cause of development, with environmental factors providing merely the right conditions for genes to act but not containing any information themselves, then the question arises how a complex organism, consisting of many different cell types, can arise from a fertilized egg, given that all cells contain the whole genome. The answer to this question that molecular biologists came to provide is that in the determination or performance of every cell type, a special set of genes is expressed. This is referred to as differential gene expression, and it leaves ample space for environmental factors to act. And yet as Evelyn Fox Keller has shown, differential gene expression quickly became associated with genetic regulation in 
the early days of molecular biology, in particular through the work of François Jacob and Jacques Monod in the 1960s. ${ }^{13}$ These researchers distinguished structural and regulatory genes, the former performing the tasks that make a cell specific, the latter being responsible for turning on or off the production of the former. Jacob and Monod described a mechanism for this type of gene-based regulation. As Keller has commented, 'By calling these mechanisms "genetic regulatory mechanisms" and not "mechanisms of gene regulation", they implied that such mechanisms are themselves genetic, laying to rest any notion that genes might rely on non-genetic factors for instructions as to when and where to act'. ${ }^{14}$ Or if such non-genetic factors act, they cannot be more than triggering cues; they do not contain the kind of information thought to be necessary for development to occur. In this context, Jacob and Monod also introduced the metaphor of a genetic programme that together with the notion of a genetic code was borrowed from the equally new discipline of computer science. ${ }^{15}$ This paradigm has been expressed by an eminent investigator of genetic regulation as follows:

The sequence content, arrangement, and other aspects of the organization of these modular control elements [of the genome] are the heritage of each species. They contain the sequence-specific code for development; and they determine the particular outcome of developmental processes and thus the form of the animal produced by every embryo. ${ }^{16}$

The notions of a genetic programme, code, or blueprint determining the development of organisms, with the environment being relegated to providing the right conditions or necessary triggers for the programme to execute itself or for the blueprint to instruct its own fulfilment, came about due to the regularity and stability of developmental processes, even under considerable fluctuation of environmental conditions. However, this view of development has been subject to harsh critique from many authors in psychology, biology, and philosophy in the last thirty or so years. It seems that these notions beg the question, insofar as it remains to be specified how the genome can function as an instruction with these properties of self-determination and the determination of a complex process. As the psychologist Susan Oyama, one of the earlier and much received critics of informational metaphors in biology has written, 'The point of the blueprint analogy, though, does not seem to be to illuminate developmental processes but rather to assume them and, in celebrating their regularity, to impute cognitive functions to the 
genes. ${ }^{17}$ More specifically, the notion of a programme does not seem well suited to explaining the spatio-temporal patterning of events. The biologist H. Frederik Nijhout has noted that 'a program must somehow contain information about the temporal sequence of events':

This criterion is never met. Development is a series of elaborate temporal and spatial interactions that are context dependent. The sequence of gene activation we see in development is an emergent property of this interaction. ${ }^{18}$

To summarize, it can be said that to explain phenotypic change and especially the origin of novelties, evolutionary theory requires more than what is acknowledged in standard conceptions of natural selection and development through differential gene expression. In other words, what is required is an account of how genetic change translates into phenotypic change and how environmental interaction plays a causal role in this process. In question is the role of the environment, not only as selective agent but also in actually shaping the phenotype during development. (In fact, such development never ends, since adult organisms also employ genetic resources according to their environmental situations and subsequently undergo permanent changes.)

\section{Phenotypic Plasticity and the Problem of Evolutionary Novelty}

Many scholars in evo-devo - the field, broadly conceived, that attempts to integrate evolutionary and developmental biology emphasize the limits of the received view as a gene-centred theory of evolution. One recurring argument is that it does not provide an explanation for evolutionary novelty:

The immediate obstacle that arises once we consider novelties as "qualitatively distinct" from existing traits is that the [modern synthesis] tells us how traits spread in natural populations (by natural selection, drift, etc.) but is silent on how they arise - except in the trivial case of quantitative variants of already existing features. ${ }^{19}$

Mary Jane West-Eberhard has mentioned that the modern synthesis misses an account of environmental induction of novelties, of mechanisms that explain how mutations translate into phenotypes, and of large-scale variants, i.e. novelties that do not arise gradually. ${ }^{20}$ While authors have differed in their definition of novelty, most mention that the feature in question should be qualitatively different from the fea- 
tures present in the organism before, not just a quantitative extension of a given feature, like a longer neck, for instance. One definition that suits the given purpose has been provided by West-Eberhard: 'An evolutionary novelty can be defined as a discrete phenotypic trait that is new in composition or context of expression relative to established ancestral traits. ${ }^{21}$

According to West-Eberhard, novelty arises when 'a novel input or initiator impinges on some individuals' in a population of genetically and phenotypically varying organisms. ${ }^{22}$ The novel input can be either a mutation or a change in the environment, and it induces some novel developmental response'. ${ }^{23}$ The point with respect to mutation is that it is not necessarily the immediate effects of a mutation but different responses of the developmental system - including the expression of non-mutated genes due to this change in the genetic context - that produce novelties. But it can also be an environmental factor that occasions a differential response of the whole system. This is what is referred to as developmental plasticity: a different phenotypic outcome on the basis of the same or almost the same genome or cellular starting conditions in different organisms, in the face of a change on the level of the genome, the cell, or the environment of the organism, to which the whole system reacts differently. West-Eberhard has illustrated this notion with the following example, though it has more pedagogical virtue in illustrating her point than epistemic significance in the study of evolution. ${ }^{24}$ In 1942, the zoologist Everhard Johannes Slijper reported the case of a goat that was born with a congenital deformation and paralysis of its forelegs but nevertheless learned to move on its hind legs alone. It is important to note that it does not matter whether the goat's deformity came about through mutation or environmental factors (although the latter is more likely). The goat's attempts to move (towards food and fellow goats) with the use of only two legs constituted a different input for the developmental processes as they typically occur in goats. The plasticity of the growth process led to a shaping of body parts that suited the goat's idiosyncratic way of moving (with respect to other goats). On dissection it was found that the hip, the spine and many other bones and muscles were very different in shape from those of other goats, and actually more like those of other bipedal mammals. Additionally, a set of tendons was observed that even represented a completely novel trait (in the sense of a novel context of expression, according to the definition above). This kind of response is pheno- 
typic accommodation - it exhibits not only plasticity but adaptive plasticity.

What these observations of the deformed goat show is that the shape of the hip, for instance, is not determined by genetic make-up. Developmental processes are selected to produce a certain outcome under certain conditions. If the conditions change, they may produce something different, without being altered by mutation. Let's assume that a novel environmental influence affects a whole population due to, say, some abrupt climatic or geological change or the migration of the whole population. Then, because of the phenotypic and genetic variation, individuals will produce different novel phenotypes in response to the new conditions, which in turn differ with respect to the degree to which they support the changed lifestyle in that very environment. There would be some organisms that accommodate better to the new circumstances than others, and they will reproduce more and pass on the genetic make-up that is supportive for the new conditions - that is, the genotype that produces the most beneficial developmental response. If the environmental influence persists and is in that sense also inherited, in the next generation there will be more individuals that exhibit the beneficial response. So in the first step, there is a selection of the variations that produce better adaptive responses. Note, however, that this is not merely a selection of the genetic variants that produces more adapted phenotypes but a selection of the genetic variants that allow for adaptive developmental responses in the face of a novel environment. But if the new input were to be removed, the old phenotype would still recur. If it persists further, genetic accommodation would occur, i.e., 'the genetic response that is expected whenever a polygenic novel or established trait comes under a new regime of natural selection'. ${ }^{25}$ New mutations or recombinations that appear would have a different value than in the situation before the novel input. They will be selected when they support the new phenotype, or rather the developmental processes that bring it about. In this way, after some time, the new phenotype will become more and more refined, and the genetic material will change to an extent that the old phenotype would not reappear if the formerly novel environmental input were removed. We can say that the new phenotype becomes canalized. ${ }^{26}$

Genetic selection thus comes in two steps: phenotypic and genetic accommodation. Phenotypic accommodation is not due to random responses to an environmental change that could be adaptive or not but 
rather consists of directed adaptation. The goat case illustrates this. The altered hip shape and the new set of tendons were induced by the environment to which they constitute an adaptation. The environment thus can be said to contain specific developmental information. While this process corresponds to views that have been labelled Lamarckian, the hypothesis of genetic assimilation makes clear that long-term evolution relies on the genetic basis of development and its replicatory features. The genotypic changes that improve the non-genetic novelty or make it more robust to environmental fluctuations become fixed through selection. This theory of evolutionary change is thus not at odds with classical Darwinism. It just puts more weight on environmental influence and on phenotypic plasticity. In a way, the phenotype takes the lead in evolution, while the genetic material follows - but evolution still consists of genetic change.

Of course, evolution rarely moves in such big steps as in the goat example, and West-Eberhard does not suggest that bipedalism in humans, for instance, originated in one such event. But the principle is scalable, and smaller changes with smaller effects might bring about novelties (though West-Eberhard does not exclude the occurrence of large-scale variants). The goat example further illustrates that in response to a new input, many changes in different traits may occur in an orchestrated manner, which leads to large changes in the organism.

\section{Epigenetics and the Molecularization of Environmental Effects}

The term 'epigenetics' most generally refers to the mechanisms of gene regulation in a cell. At any given moment in the life of an organism, gene expression is governed by the molecular conditions in the cell. As mentioned above, regulatory mechanisms and networks have been studied since the early days of molecular biology, with the operon model suggested by Jacob and Monod in 1962 as a paradigm case, leading to complex wiring diagrams of gene regulatory systems. ${ }^{27}$ Gene regulation is dependent on products of earlier expression of genes (the transcription of parts of the genome to functional RNA molecules and the translation of some RNA in proteins) either in the same cell or in other cells, in the case of signalling molecules that can travel between cells. Furthermore, in early development, RNA and proteins, which are already expressed in the gametes (sperm and egg) at the point of fertilization, regulate gene expression. These gene products act through sev- 
eral mechanisms, some of which operate on the level of DNA, facilitating or blocking translation; some manipulate already expressed RNA molecules or proteins that might themselves be involved in regulation.

These aspects of gene regulation still fit well within the older paradigm of a genetic programme executing itself. But it has become increasingly clear in the last few years that the very packaging of DNA as well as several other aspects of the biochemical and physical conditions in and around the cell influence regulation. Here, another aspect of gene regulation comes in that can involve other molecules and metabolic processes beyond RNA and proteins. These mediate the influence of food digestion and other environmental factors on a molecular level. Therefore, much work under the heading of epigenetics now puts more emphasis on the influence of the environment in development and physiological processes, in particular the shaping of individual variation with respect to various characters, including pathologies - in short, on the role of environmental regulatory factors in the plasticity of organisms. Plasticity as discussed above points to the effects of environmental influence, but epigenetics emphasizes the molecular mechanisms that mediate environmental factors and cellular processes. What is particularly interesting is that cases have been experimentally confirmed and mechanisms have been elucidated that show how environmental influence can be inherited, even if the environmental aspect that introduced a change does not affect later generations. Eva Jablonka and Gal Raz have called this 'transgenerational epigenetic inheritance'. ${ }^{28}$ It is the last two aspects of epigenetics, the influence of individual environments on a molecular level and the possibility of the inheritance of its effects, that constitute for many - biologists as much as other commentators - the most interesting and challenging developments in current epigenetic studies. Let us therefore characterize epigenetic inheritance systems in some more detail.

While epigenetic inheritance in a broad sense can include inheritance through recurring developmental interactions between mother and offspring, social learning, and symbolic communication, ${ }^{29}$ there is also a more specific concept of cellular epigenetic inheritance. It refers to "the transmission from mother cell to daughter cell of variations that are not the result of differences in DNA base sequence and/or the present environment'. ${ }^{30}$ Two epigenetic inheritance systems for multicellular organisms are the transmission in cell division of molecules that are attached to DNA or to proteins that package and order DNA on the 
one hand and of regulatory RNAs on the other. These mechanisms can explain how differentiated cells give rise to identical daughter cells even if the signal that initiated differentiation is gone. But even more interesting is cellular transgenerational epigenetic inheritance. In such cases, 'The environment may induce epigenetic variation by directly affecting the germline or by affecting germ cells through the mediation of the soma, but, in either case, subsequent transmission is through the germline. ${ }^{31}$ As Maurizio Meloni and Giuseppe Testa have commented in reference to August Weismann, who introduced the distinction between soma and germline that underlies a gene-centred perspective in biology, 'The epigenetic body brings the Weismannian body to an end.'32

\section{Plasticity, Epigenetics, and Genetic Specificity}

There is of course still much to be said about the developmental processes that allow for plasticity. West-Eberhard has emphasized that existing processes and structures are expressed in different places or at different points in development: 'The origin of novelty is reorganizational, a product of reexpression of preexisting sets of genes. ${ }^{33}$ The new tendons in the aforementioned goat, for instance, grew by employing the molecular and developmental mechanisms that are usually involved in growing tendons in other places in typical goats. Gerd Müller has also noted novelties arising from 'the redeployment of any of these components [molecular or developmental modes and interactions] at new locations, through subdivision or combination of earlier structures, or through developmental individualization of a serial structure'. ${ }^{34}$ Marc Kirschner and John Gerhart, discussing the notion of evolvability, have mentioned exploratory processes: nerves and blood vessels, for instance, grow in a random manner and become established only when they receive the right signal; otherwise they get reduced again. ${ }^{35}$ In this way, they can easily accommodate changes in, say, appendages, without the need 'to wait for the right mutation' to programme growth in the new regions. The picture that emerges from these points is that the plasticity of development requires stable developmental routines that are invariant to the environmental influence bringing about the plastic response, and thus the routines appear as quite determined.

Turning to epigenetics again, we can observe that epigenetic research can hardly be described in Kuhnian (i.e., strongly discontinuous) terms of revolutionary developments in science. And the extent to 
which findings in epigenetics change the picture in biology is unsurprisingly subject to controversy, ${ }^{36}$ since every sensitivity to environmental input seems after all to presuppose some genetic condition, and every change it may bring about is mediated by genes or their immediate products. There must be proteins that set and remove epigenetic modifications of the genome, and after all, the effect of the latter is achieved by allowing or blocking the transcription of genes. The opposition to gene-centrism might thus rather appear as a Gestalt switch or as a change of emphasis in the relation of genes and environment, the existence of which has always been acknowledged. However, a different perspective and parsing of phenomena will result in alternative decisions and activities and finally will make research take different directions. Even if one wishes to argue that the gene-centred view of biology remains untouched in the light of epigenetics, epigenetic research has clearly extended the range of studies on gene regulation and shifted the focus on environment and individual variation in some fields, especially biomedicine. We can, however, be less reserved concerning the changes in biology and observe that a conceptual shift has taken place such that the genome is viewed less as a programme and more as a reactive agent. ${ }^{37}$ Still, it seems that the elucidation of the mechanisms of environmental influence on gene expression does not diminish the role of genes in facilitating specific responses to these environmental inputs. In the following, we will start from the concept of innateness and its critique in terms of plasticity and epigenetics to arrive at a similar conclusion.

\section{INNATENESS, PHENOTYPIC PLASTICITY, AND EPIGENETICS IN THE COGNITIVE SCIENCES}

Usually, innateness is associated with determinism, fixity, or robustness. A trait is said to be innate when its development is genetically specified, when it develops in large sets of environments, or when it is buffered against environmental variations. Innateness understood in this way is not consistent with what seems to be characteristic of organisms: phenotypic plasticity. Organisms possess the capacity to adapt to environmental variations in developing alternative phenotypes. Because the plasticity of organisms seems to imply that every trait is acquired and not innate, some researchers hold that this concept is superfluous 
and should be rejected. ${ }^{38}$ However, this picture turns out to be too simplistic when one inquires into the position of nativists, that is, of philosophers and cognitive scientists who claim that the mind is endowed with innate faculties. Indeed, while they maintain that the faculties of the mind are innate, they never deny the necessary intervention of the environment in the development of these traits. For example, when Noam Chomsky talks about an innate faculty of language, he does not mean that language can develop without linguistic environment. ${ }^{39} \mathrm{He}$ claims only that this environment does not provide all the information needed for language development to occur. Thus, even within a nativist framework, language development remains a plastic phenomenon, since it depends on the specific environment in which it occurs. This is evidenced by the diversity of languages that human beings are able to learn, depending on the particular linguistic environments in which they live. With this in mind, it is worth asking how exactly innateness and plasticity should be articulated in order to understand their complementary character.

\section{Two Arguments Invoking Plasticity in Order to Dismiss Innateness}

Plasticity has been invoked in two ways to dismiss innateness ascriptions. First, it has been used generally to reject innateness as a scientific concept. Second, it has been used specifically, as in the case of brain plasticity, to show that most traits are acquired and not innate.

\section{a) The Broader Argument about the Complexity of Ontogeny}

The complexity of ontogeny is used by developmental system theorists to highlight the problematic meaning of 'genetic specification', which underlies the notion of innateness. ${ }^{40}$ Indeed, when researchers talk about 'innate traits' they generally mean 'genetically specified traits'. ${ }^{41}$ For example, Chomsky holds that innate universal grammar is genetically specified. ${ }^{42}$ But it is very difficult to give a satisfactory definition of genetic specification, since it is either too strong or too weak. This is due to the epigenetic dimension of development.

As said in the introductory section of this article, 'epigenetics' can be understood in two ways. We discussed above the narrow sense of epigenetics as the control of gene activity by molecular mechanisms. In a broad sense, epigenetics is a bridge between genotype and phenotype showing that there are triadic interactions between gene, organism, and 
environment and emphasizing the complex and emergent character of development. In both cases, epigenetics is a reaction against the insufficiency of genetics, ${ }^{43}$ insofar as epigenetics highlights either the specific inability to offer plausible mechanisms of the control of gene activity in development or the general incapacity to explain the genesis of the phenotype from the genotype. These incapacities of standard views of genetic information or gene action become obvious in the face of the plasticity of development, i.e., the sensitivity to internal and external environments, which is addressed by epigenetics.

Every phenotypic trait is the joint product of genes and environment. This 'interactionist consensus' centres around the belief that every trait is somehow the expression of the genome in a specific environment. ${ }^{44}$ Ontogeny results from the complex combination between interacting genotypic causes and environmental causes. But boundaries between both types of causality are very difficult to draw. As noticed earlier, among causal factors, some are epigenetic - they control and regulate gene activity. Every genomic expression, because it is dependent on epigenetic factors, is contextual. Boundaries of genes are moved: ${ }^{45}$ a gene becomes the whole formed by coding sequences and regulating signals. Then environmental influences in early infancy can alter epigenetic processes and thus change the expression of individual DNA.

Nevertheless, for Paul Griffiths, the 'interactionist consensus' encapsulates two wrong ideas about development. ${ }^{46}$ First, it divides causes of development into two symmetrical causes - genes and environment. Second, it implicitly advocates that genes are predominant for explanation. Developmental systems theory refuses to treat genes as a special factor with predominant causal role in development. The epigenetic character of development forces us to recognize the dependence of individual ontogeny vis-à-vis multiple 'developmental resources'. ${ }^{47}$ The 'parity thesis' asserts the same significance of all developmental resources in development. ${ }^{48}$ It recognizes the intervention of multiple interacting developmental resources in a self-organized, plastic, and contingent process. Some of these developmental resources are genetic. Others include non-genetic components as varied as the cytoplasm of a zygote or social events. Furthermore, major resources are provided by early stages of the developmental process itself.

In this perspective, innateness is viewed as an inadequate concept that cannot account for the complexity of ontogeny. The notion of 
innateness would always imply the predominance of one causal factor, i.e., the genetic factor, which, however, according to this line of critique, is not separable from other causes. Innateness ascriptions, then, promote a static vision of development. Carrying a too restrictive vision of causality, innateness fails to apply adequately to development, which seems to involve different components, operations, and interactions and is fundamentally plastic. The consequence seems to be that the notion of innateness impairs the study of development.

However, this general argument, which employs epigenetics or plasticity in order to dismiss innateness, is relevant only for an account of innateness that relies on a dominant causal factor. But it appears that every trait is the product of several factors, including innate factors. It results from reciprocal interactions between varied elements of the developmental system. Thus, reference to epigenetics or plasticity does not justify dismissing innateness. Innateness can be compatible with a non-restrictive view of causality in an adequate account of development. Innate endowment of organisms would refer to a repertory of endogenous developmental resources that can interact with other developmental resources to produce phenotypic traits. As a developmental resource among others, innate mechanisms or constraints have no explanatory priority.

\section{b) The Specific Argument Based on Brain Plasticity}

Another anti-nativist trend purports to show that neural plasticity contradicts the hypothesis of innate knowledge. ${ }^{49}$ Neural plasticity is a special kind of plasticity, since it reveals the ability of a unique genotype to produce more than one phenotype..$^{50}$ According to the neurobiological argument based on brain plasticity, the extreme plasticity of the brain during cortical development makes the existence of innate cognitive structures highly improbable. The human brain is a plastic organ, in its development and in its functioning. More precisely, the plasticity of the human brain points to two things: the significance of environmental stimulation in shaping neural circuitry, and the capacity of the brain to reorganize itself and accomplish the same tasks in different ways.

Steven Quartz and Terrence Sejnowski have shown that fundamental aspects of neural organization develop in a manner that is highly sensitive to the environment. ${ }^{51}$ Neural plasticity enables us to learn efficiently in unpredictable environments. Ontogenetic sculpture of neuro- 
nal connections depending on experience is a major aspect of cerebral growth during infancy. For example, when the brain is deprived of visual stimulation because one eye is kept closed, this eye will end up functionally blind. Environmental stimulations play a major role in shaping cortical circuitry. At the same time, the cortical system has more than one way to form specialized circuitry. The realized pathway is probably never the same in two individuals. Different environments imply different neural organizations, even in the case of similar starting points. These differences are deep and exist at a variety of scales. Thus, learning capacities are not 'stationary'. ${ }^{52}$ The very ways that humans learn change as long as learning takes place. Minds have contingent but stable features: they develop in some circumstances but persist once they are developed. The system possesses a kind of cortical memory, i.e., the repeating exposure to the same inputs consolidates the specialization of the circuitry.

Furthermore, to accomplish the same tasks, we use different brain areas at different ages. Brain plasticity is also the capacity of brain regions to fulfil different functions, to reconfigure themselves in response to environmental demands. When a cortical region changes its function (for example, after the amputation or lesion of a part), it does so not by creating new connections but by activating latent connections that were inactive until this point. Functional properties of neurons of the cerebral cortex are dynamical, modifying themselves constantly under the effect of experience. ${ }^{53}$ Brains continue to grow and reorganize themselves continuously in response to environmental input.

In a nutshell, specialized cortical circuitry seems to emerge from interaction with environment without being guided by innate rules. For David J. Buller, learning is strictly conditioned by interactions between endogenous activity of the brain and patterns of environmental stimuli. ${ }^{54}$ The precise patterns of environmental stimuli to which the developing cortex is exposed play a major role in the shaping of brain circuitry and their functional properties. Environmental inputs shape finegrained structures by a selection of cells. Neural plasticity shapes adaptive complex cognitive structures without genetic specification. ${ }^{55}$ As connections change and cells die, domain-specific competences, e.g., competences that are dedicated to fulfil specific tasks, must emerge as an a posteriori product. The contingency of the connection patterns seems to reveal the absence of predetermination and thus of innateness. In this perspective, if mind specialization is a posteriori shaped by envi- 
ronment, innate knowledge is not necessary for learning, and the mind does not contain genetically specified, i.e., innate, faculties. Specialized cortical circuits are built solely by the plastic interaction between the brain and its local environment.

The two arguments discussed suggest that ascriptions of innateness and the plasticity of traits, such as mental faculties, contradict each other. In the following sections, we argue for a way that innateness can nonetheless be reconciled with plasticity, especially with respect to learning.

\section{Why Plasticity Needs Innateness}

Our main argument is that plasticity does not imply that everything is possible and, further, that innateness is a useful concept for addressing the factors that limit the number of possible outcomes of a process.

\section{a) Plasticity Does Not Rule Out Innateness}

Some constructivist accounts reconcile notions of acquired and innate traits. For example, Annette Karmiloff-Smith has held a constructivist account of language development. ${ }^{56}$ In her view, linguistic knowledge results from an epigenetic process: it progressively constructs itself during development. But this development still requires innate linguistic predispositions that orientate or at least allow for the further construction of specific linguistic representations. As in morphological development (discussed above), the influence of environmental factors as studied in epigenetics needs genetic specificity. Furthermore, environmental interaction and even learning is always under genetic control: neural cell stimulation triggers the expression of genes, which either directly modifies the structure and function of synapses or triggers the expression of other genes. Even those who highlight the epigenetic dimension of development usually accept the significance of genes and the necessity of constraints, and these constraints, we argue, can be considered innate. Franck Ramus has commented:

Plasticity, and brain plasticity in particular, has a meaning only within strict genetic control: Ironically, plasticity is among the properties of the brain that must be under the tightest genetic control. [...] In a nutshell, plasticity is not an alternative to the genome, indeed it is entirely controlled by the genome. ${ }^{57}$ 
Brain plasticity is not the shaping of an initially unformed mass under the effects of environment. The cortex does possess an intrinsic structure. $^{58}$ The paradigmatic example of plasticity, namely the column of ocular dominance, illustrates this: in a first phase, columns are formed under genetic control without the need of visual stimulations. In macaques, this has been shown to happen even before birth. The critical period during which there is plasticity comes afterwards (e.g., if one eye is permanently closed, the column will disappear). And even here, the mechanisms employed for building structures in a plastic and responsive manner need to be in place. At the end of this period, the system becomes buffered against environmental stimulations. The point is that neural tissues are not similar to substances that can take whatever form, for example, modelling clay.

b) The Necessity of Initial Constraints in Learning: Irreducible Minimal Nativism

When we turn from brain structure to the capacity to learn, it appears that instead of an opposition, there is complementarity between innate constraints and learning. Even learning requires some innate mechanisms. ${ }^{59}$ James Gould and Peter Marler have held, 'The animal is innately equipped to recognize when it should learn, what cues it should attend to, how to store the new information and how to refer to it in the future. ${ }^{60}$ These 'instincts to learn' are located within the interaction between genome and environment. Even the most arbitrary culturally transmitted behaviour might be the result of an 'instinct', not in its specific expression of course, but with respect to the ability to acquire it. What is in question is not the existence of these instincts but rather their nature and their mechanisms. Each species of bird, for example, learns songs in a way that suits their nature. Within each, innate specifications contribute to song acquisition without obviating the need of learning.

At this point, a caveat is in order. Nativism, strictly speaking, has to be distinguished from the use of the concept of innateness. Nativism is a specific view of mind structure, a specific view of what has to be innate. It posits the existence of innate domain-specific faculties, which constitutes a very strong claim. But even an empiricist account of mind structure - i.e., an account that claims that the mind is not endowed with innate domain-specific faculties - needs a concept of innateness 
and thus needs to admit a minimal nativism. ${ }^{61}$ An empiricist has to postulate at least the existence of innate learning mechanisms or capacities. ${ }^{62}$ Even Buller, who defends a radical anti-nativist account, has admitted the existence of initial tendencies in the mind that orientate attention on relevant environmental inputs. Learning is helped by these initial biases that make the organism aware of stimuli. These few initial biases are the head-starts of learning. Thus, the difference between strict nativism and anti-nativism does not deal with the existence of innate structure but with its nature: is it composed of domain-specific capacities or of general-purpose learning mechanisms? As Carruthers has remarked, 'The real debate about language acquisition is not about whether a nativist model is correct but rather about which sort of nativist model is correct. ${ }^{63}$

Strict nativists see the mind as the product of a relatively large number of innately specified, relatively complex, domain-specific structures and processes. Empiricists see the mind as a set of general-purpose learning mechanisms. ${ }^{64}$ Empiricism does not dismiss all innateness. It rejects only specific innate content. Accordingly, we can defend the concept of innateness without necessarily adopting a strict nativist account.

\section{What Kind of Innateness is Compatible with Plasticity?}

Plasticity, then, needs innateness, but innateness, to be compatible with plasticity, should not be understood as determinism, fixity, or robustness of specific outcomes of development or learning. Constructivists have adopted the notion of innate 'biases' to make innateness compatible with plasticity. Innate biases allow for plastic responses since they do not contain in themselves the final state of development, ${ }^{65}$ but they orientate development in a sense, since they refer to an innate endowment that enables the organism to reach some content within a specific range of possibilities. As noted earlier, Karmiloff-Smith has proposed a model of acquisition of knowledge that requires linguistic predispositions guiding the progressive construction of specific linguistic representations. But the construction process goes much beyond what the linguistic predispositions are about. It is a process of 'reiterative representational re-description' during which implicit information in the mind progressively becomes more explicit for the consciousness. In this model, development is much more than the mere unfolding of innate 
content. And initial biases (linguistic predispositions) largely differ from the final state (linguistic knowledge). Therefore, they are neither a set of innate grammatical rules nor a mere general aptitude to learn language. Linguistic knowledge is constructed through a process of representational re-description from the interaction between innate biases and environment.

Clearly, innate biases posited by constructivists are more flexible than innate constraints in strict nativist accounts. They can still be domain-specific though, since they orient attention on a certain type of data. Studies in cognitive psychology suggest that infants are cognitively predisposed to interpret the world in terms of agents and objects. ${ }^{66}$ But the innate biases that an infant possesses enable flexibility, since they do not determine the final state. They are thus perfectly compatible with and even necessary for the emergence of new structures: they are likely to be modified. Initial beliefs about the world upon interaction with the environment produce an understanding that will entail their reassessment. Infants come to the world with some biases, which they use to give meaning to their experience and to make some predictions; during development, they become able to compare their early predictions with their further experiences and then to improve them by producing more precise expectations. ${ }^{67}$

William James, who is known to be the first to apply plasticity to behaviour, has expressed this meaning of plasticity in precise terms:

Plasticity, then, in the wide sense of the word, means the possession of a structure weak enough to yield to an influence but strong enough not to yield all at once. Each relatively stable phase of equilibrium in such a structure is marked by what we may call a new set of habits. ${ }^{68}$

According to James, plasticity is the condition for developing a new set of habits. However, the rejection of the notion of a predetermination of features often mobilizes a notion of plasticity as the capacity to acquire any possible form and to do so only through the action of the environment. But as noted earlier, plasticity is always constrained. Conversely, innateness need not be understood as complete determinism. It should be used to refer to a set of mechanisms and constraints that does not prefigure the end result of development but rather enables the constructive process that will lead to the appearance of the trait. Plasticity and innateness can then both be defined as two facets of the same phenomenon of determined flexibility. 
Strictly speaking, it is then not possible to speak of 'innate phenotypic traits'. Indeed, most traits co-vary with environmental factors and are the result of complex interactions between several developmental resources. Most phenotypic traits - morphological, behavioural, or concerning mental content - cannot be qualified as innate, since their appearance requires the intervention of multiple factors, of which only some are innate. These innate factors can be assimilated to some developmental resources within organisms, which through a complex interaction with other factors, make possible the developmental cascade leading to the appearance of a trait. Thus, innateness can mainly concern the capacities or dispositions of organisms, not their forms or mental content. The notion of capacity/disposition can embody this determined flexibility characteristic of development. It refers both to ranges of possibilities and to some specific end results that organisms are disposed to acquire. A general capacity to acquire everything is not helpful in explaining development.

Innate capacities are the initial capacities that a satisfactory developmental explanation will attribute to an organism in order to render interaction with other developmental resources possible. Innate capacities are what enable the developmental process to produce its outcome in response to the environment. Thus, innateness belongs to the condition of explanation, as a capacity the organism must have to be able to develop a trait properly. ${ }^{69}$ From the point of view of ontogeny, the influence of some innate entities and operations appears to be necessary for development to occur. Innateness deals with starting capacities that can lead to several results.

\section{CONCLUSION}

Acknowledging the significance of environmental influence in morphological and cognitive development and evolution in terms of epigenetics and plasticity should not be understood as saying that every outcome is possible. Plasticity is always constrained, and it requires developmental subroutines and mechanisms to built novel structures. Some of these mechanisms, once activated, act quite autonomously from environmental modification, while others are altered, for instance, with respect to dosage of expression. Epigenetics is concerned with the mediation of environmental influence and genomic resources resulting in plastic 
responses. However, this mediation relies again on relatively robust mechanisms that translate environmental factors into molecular modifiers of regulation. Thus, plasticity and its epigenetic mediation act through stable resources and robust mechanisms based on the stability of the content and structure of the genetic material. In this sense, they presuppose what can be called innate, or to a certain degree, genetically determined, elements. Conversely, innateness and genetic determination from this perspective are not understood as completely determining the outcome of development. Instead, they apply to some developmental resources and processes, mainly on the cellular level. Accordingly, we conclude that it is important to study the influence of the environment in biology, medicine, and the cognitive science and to move away from gene-centred explanations of evolutionary change, developmental processes, and pathologies primarily in terms of mutation or gene action. We point out, however, that explanations of the outcome of development and evolution will require reference to stable and robust features that are derived from the stability of the genome. The two cases of development and evolution of morphological form on the one hand and cognitive development and learning on the other hand, despite all differences, point in the same direction in this respect.

\section{NOTES}

1 See Martyn Pickersgill, Jörg Niewöhner, Ruth Müller, Paul Martin, and Sarah Cunningham-Burley, 'Mapping the New Molecular Landscape: Social Dimensions of Epigenetics', New Genetics and Society, 32.4 (2013), pp. 429-47; Sigrid Weigel, 'An der Schwelle von Kultur und Natur. Epigenetik und Evolutionstheorie', in Evolution in Natur und Kultur, ed. by Volker Gerhardt and Julian NidaRümelin (Berlin: de Gruyter, 2010), pp. 103-23; Catherine Malabou, What Should We Do with Our Brain?, trans. by S. Rand (New York: Fordham University Press, 2008).

2 Maurizio Meloni and Giuseppe Testa, 'Scrutinizing the Epigenetics Revolution', BioSocieties, 9 (2014), pp. 431-56.

3 Sheila Jasanoff, 'The Idiom of Co-Production', in States of Knowledge: The CoProduction of Science and the Social Order, ed. by Sheila Jasanoff (London: Routledge, 2004), pp. 1-12.

4 Carlos Novas and Nikolas Rose, 'Genetic Risk and the Birth of the Somatic Individual', Economy and Society, 29.4 (2000), pp. 485-513.

5 Conrad H. Waddington, 'The Epigenotype', Endeavour, 1 (1942), pp. 18-20. See also Eva Jablonka and Marion J. Lamb, Evolution in Four Dimensions: 
Genetic, Epigenetic, Behavioral, and Symbolic Variation in the History of Life (Cambridge, MA: MIT Press, 2005).

6 Kim Sterelny and Paul E. Griffiths, Sex and Death: An Introduction to Philosophy of Biology (Chicago: University of Chicago Press, 1999).

7 Massimo Pigliucci and Gerd B. Müller, Evolution: The Extended Synthesis (Cambridge, MA: MIT Press, 2010).

8 Massimo Pigliucci, 'Genotype-Phenotype Mapping and the End of the "Genes as Blueprint” Metaphor', Philosophical Transactions of the Royal Society B, 365 (2010), pp. 557-66.

9 David L. Hull, Rodney E. Langman, and Sigrid S. Glenn, 'A General Account of Selection: Biology, Immunology, and Behavior', Behavioral and Brain Sciences, 24.3 (2001), pp. 511-28 (p. 513).

10 Ibid., p. 517.

11 Lindley Darden and Joseph A. Cain, 'Selection Type Theories', Philosophy of Science, 56.1 (1989), pp. 106-29.

12 Ibid., p. 112.

13 Evelyn Fox Keller, The Century of the Gene (Cambridge, MA: Harvard University Press, 2000).

14 Ibid., p. 79.

15 Lily E. Kay, Who Wrote the Book of Life? A History of the Genetic Code (Stanford: Stanford University Press, 2000).

16 Eric H. Davidson, The Regulatory Genome: Gene Regulatory Networks in Development and Evolution (Burlington, MA: Academic Press, 2006), p. 2.

17 Susan Oyama, The Ontogeny of Information: Developmental Systems and Evolution (Durham, NC: Duke University Press, 2000), pp. 54-55.

18 H. Frederik Nijhout, 'Metaphors and the Role of Genes in Development', BioEssays, 12.9 (1990), pp. 441-46 (p. 443).

19 Massimo Pigliucci, 'What, If Anything, Is an Evolutionary Novelty?', Philosophy of Science, 75.5 (2008), pp. 887-98 (p. 889). A similar point is made by Gerd B. Müller, 'Novelty and Key Innovation', in Encyclopedia of Evolution, ed. by M. Pagel (Oxford: Oxford University Press, 2002), pp. 827-30 (p. 828).

20 Mary Jane West-Eberhard, 'Toward a Modern Revival of Darwin's Theory of Evolutionary Novelty', Philosophy of Science, 75.5 (2008), pp. 899-908 (p. 903).

21 Ibid., p. 899, italics in the original.

22 Ibid., p. 904.

23 Ibid., p. 905.

24 See Mary Jane West-Eberhard, 'Phenotypic Accommodation: Adaptive Innovation Due to Developmental Plasticity', Journal of Experimental Zoology, 304b (2005), pp. 610-18.

25 West-Eberhard, 'Toward a Modern Revival', p. 906.

26 Conrad H. Waddington, 'Canalization of Development and the Inheritance of Acquired Characters', Nature, 150.3811 (1942), pp. 563-65.

27 Davidson, The Regulatory Genome. 
28 Eva Jablonka and Gal Raz, 'Transgenerational Epigenetic Inheritance: Prevalence, Mechanisms, and Implications for the Study of Heredity and Evolution', The Quarterly Review of Biology, 84.2 (2009), pp. 131-76.

29 Jablonka and Lamb, Evolution in Four Dimensions; Ehud Lamm, 'Inheritance Systems', in The Stanford Encyclopedia of Philosophy (Spring 2014 edition), ed. by E.N. Zalta, <http://plato.stanford.edu/archives/spr2014/entries/inheritancesystems> [accessed 5 Febuary 2016].

30 Jablonka and Raz, 'Transgenerational Epigenetic Inheritance', p. 132.

31 Ibid., p. 133.

32 Meloni and Testa, 'Scrutinizing the Epigenetics Revolution', p. 449.

33 West-Eberhard, 'Toward a Modern Revival', p. 906.

34 Müller, ‘Novelty and Key Innovation’, p. 828.

35 Marc Kirschner and John Gerhart, 'Evolvability', PNAS, 95 (1998), pp. 842027.

36 Meloni and Testa, 'Scrutinizing the Epigenetics Revolution'.

37 Paul Griffiths and Karola Stotz, Genetics and Philosophy: An Introduction (Cambridge: Cambridge University Press, 2013).

38 Oyama, The Ontogeny of Information; Paul Griffiths, 'What Is Innateness?', The Monist, 85.1 (2002), pp. 70-85.

39 Noam Chomsky, Rules and Representations (Cambridge, MA: MIT Press, 1980).

40 Oyama, The Ontogeny of Information; Paul Griffiths and Russel Gray, 'Developmental Systems and Evolutionary Explanation', The Journal of Philosophy, 91.6 (1994), pp. 277-304.

41 Steven Pinker, The Language Instinct (New York: William Morrow, 1994); Jerry Fodor, The Modularity of Mind (Cambridge, MA: MIT Press, 1983); Chomsky, Rules and Representations.

42 Chomsky, Rules and Representations.

43 Michel Morange, 'Quelle place pour l'épigénétique?', Médecine/science, 21 (2005), pp. 367-69.

44 Russel Gray, 'Death of the Gene: Developmental Systems Strike Back', in Trees of Life: Essays in the Philosophy of Biology, ed. by Paul E. Griffiths (Dordrecht: Kluwer, 1992), pp. 165-209.

45 Michel Morange, La part des genes (Paris: Editions Odile Jacob, 1998).

46 Griffiths, 'What Is Innateness?'.

47 Ibid.; Oyama, The Ontogeny of Information.

48 Oyama, The Ontogeny of Information.

49 Jeffrey L. Elman, et al., Rethinking Innateness: A Connectionist Perspective on Development (Cambridge, MA: MIT Press, 1996); Steven Quartz and Terrence J. Sejnowski, 'The Neural Basis of Cognitive Development: A Constructivist Manifesto', Behavioral and Brain Sciences, 20 (1997), pp. 537-96.

50 David J. Buller, Adapting Minds (Cambridge, MA: MIT Press, 2005).

51 Quartz and Sejnowski, 'The Neural Basis of Cognitive Development'.

52 Ibid. 
53 Annette Karmiloff-Smith, 'Bates's Emergentist Theory and Its Relevance to Understanding Genotype/Phenotype Relations', in Beyond Nature-Nurture: Essays in Honor of Elizabeth Bates, ed. by M. Tomasello and D. Slibin (Mahwah, NJ: Lawrence Erlbaum Associates, 2005), pp. 219-36.

54 Buller, Adapting Minds.

55 Ibid.

56 Annette Karmiloff-Smith, Beyond Modularity: A Developmental Perspective on Cognitive Science (Cambridge, MA: MIT Press, 1992).

57 Franck Ramus, 'Genes, Brain, and Cognition: A Roadmap for the Cognitive Scientist', Cognition, 101 (2006), pp. 247-69 (p. 256).

58 Pinker, The Language Instinct.

59 Ned Block, 'Introduction: What Is Philosophy of Psychology?', in Readings in Philosophy of Psychology, ed. by Ned Block (Cambridge, MA: Harvard University Press, 1981), II, pp. 1-8.

60 James L. Gould and Peter Marler, 'Learning by Instinct', Scientific American, 256.1 (1987), pp. 62-73 (p. 73).

61 Richard Samuels, 'What Brains Won't Tell Us about the Mind: A Critique of the Neurobiological Argument against Representational Nativism', Mind \& Language, 13.4 (1998), pp. 548-70.

62 Block, 'What Is Philosophy of Psychology?'.

63 Peter Carruthers, Stephen Laurence, and Stephen Stich, The Innate Mind: Structure and Contents (Oxford: Oxford University Press, 2005), p. 7.

64 Ibid.

65 Karmiloff-Smith, Beyond Modularity.

66 Alison Gopnik, Andrew N. Meltzoff, and Patricia K. Kuhl, The Scientist in the Crib: Minds, Brains, and How Children Learn (New York: William Morrow, 1999).

67 Ibid.

68 William James, The Principles of Psychology (New York: H. Holt, 1890), p. 105.

69 Valentine Reynaud, 'Can Innateness Ascriptions Avoid Tautology?', Philosophia Scientiae, 18.3 (2014), pp. 177-90. 
Robert Meunier and Valentine Reynaud, 'The Innate Plasticity of Bodies and Minds: Integrating Models of Genetic Determination and Environmental Formation', in De/Constituting Wholes: Towards Partiality Without Parts, ed. by Christoph F. E. Holzhey and Manuele Gragnolati, Cultural Inquiry, 11 (Vienna: Turia + Kant, 2017), pp. 151-76 <https://doi.org/10.37050/ci-11_08>

\section{REFERENCES}

Block, Ned, 'Introduction: What Is Philosophy of Psychology?', in Readings in Philosophy of Psychology, ed. by Ned Block (Cambridge, MA: Harvard University Press, 1981), II, pp. 1-8

Buller, David J., Adapting Minds (Cambridge, MA: MIT Press, 2005)

Carruthers, Peter, Stephen Laurence, and Stephen Stich, The Innate Mind: Structure and Contents (Oxford: Oxford University Press, 2005)

Chomsky, Noam, Rules and Representations (Cambridge, MA: MIT Press, 1980)

Darden, Lindley and Joseph A. Cain, 'Selection Type Theories', Philosophy of Science, 56.1 (1989), pp. 106-29 <https://doi.org/10.1086/289475>

Davidson, Eric H., The Regulatory Genome: Gene Regulatory Networks in Development and Evolution (Burlington, MA: Academic Press, 2006) <https://doi.org/10.1016/B978012088563-3.50022-5>

Elman, Jeffrey L., et al., Rethinking Innateness: A Connectionist Perspective on Development (Cambridge, MA: MIT Press, 1996)

Fodor, Jerry, The Modularity of Mind (Cambridge, MA: MIT Press, 1983)

Gopnik, Alison, Andrew N. Meltzoff, and Patricia K. Kuhl, The Scientist in the Crib: Minds, Brains, and How Children Learn (New York: William Morrow, 1999)

Gould, James L. and Peter Marler, 'Learning by Instinct', Scientific American, 256.1 (1987), pp. $62-$ 73

Gray, Russel, 'Death of the Gene: Developmental Systems Strike Back', in Trees of Life: Essays in the Philosophy of Biology, ed. by Paul E. Griffiths (Dordrecht: Kluwer, 1992), pp. 165-209

Griffiths, Paul, 'What Is Innateness?', The Monist, 85.1 (2002), pp. 70-85

Griffiths, Paul and Karola Stotz, Genetics and Philosophy: An Introduction (Cambridge: Cambridge University Press, 2013)

Griffiths, Paul and Russel Gray, 'Developmental Systems and Evolutionary Explanation', The Journal of Philosophy, 91.6 (1994), pp. 277-304

Hull, David L., Rodney E. Langman, and Sigrid S. Glenn, 'A General Account of Selection: Biology, Immunology, and Behavior', Behavioral and Brain Sciences, 24.3 (2001), pp. 511-28 <https://doi.org/10.1017/S0140525X01004162>

Jablonka, Eva and Gal Raz, 'Transgenerational Epigenetic Inheritance: Prevalence, Mechanisms, and Implications for the Study of Heredity and Evolution', The Quarterly Review of Biology, 84.2 (2009), pp. 131-76

Jablonka, Eva and Marion J. Lamb, Evolution in Four Dimensions: Genetic, Epigenetic, Behavioral, and Symbolic Variation in the History of Life (Cambridge, MA: MIT Press, 2005)

James, William, The Principles of Psychology (New York: H. Holt, 1890)

Jasanoff, Sheila, 'The Idiom of Co-Production', in States of Knowledge: The Co-Production of Science and the Social Order, ed. by Sheila Jasanoff (London: Routledge, 2004), pp. 1-12<https: //doi.org/10.4324/9780203413845> 
Karmiloff-Smith, Annette, 'Bates's Emergentist Theory and Its Relevance to Understanding Genotype/Phenotype Relations', in Beyond Nature-Nurture: Essays in Honor of Elizabeth Bates, ed. by M. Tomasello and D. Slibin (Mahwah, NJ: Lawrence Erlbaum Associates, 2005), pp. 219-36

Beyond Modularity: A Developmental Perspective on Cognitive Science (Cambridge, MA: MIT Press, 1992)

Kay, Lily E., Who Wrote the Book of Life? A History of the Genetic Code (Stanford: Stanford University Press, 2000)

Keller, Evelyn Fox, The Century of the Gene (Cambridge, MA: Harvard University Press, 2000)

Kirschner, Marc and John Gerhart, 'Evolvability', PNAS, 95 (1998), pp. 8420-27

Lamm, Ehud, 'Inheritance Systems', in The Stanford Encyclopedia of Philosophy (Spring 2014 edition), ed. by E.N. Zalta, <http://plato.stanford.edu/archives/spr2014/entries/ inheritance-systems $>$ [accessed 5 Febuary 2016]

Malabou, Catherine, What Should We Do with Our Brain?, trans. by S. Rand (New York: Fordham University Press, 2008)

Meloni, Maurizio and Giuseppe Testa, 'Scrutinizing the Epigenetics Revolution', BioSocieties, 9 (2014), pp. 431-56 <https://doi.org/10.1057/biosoc.2014.22>

Morange, Michel, La part des genes (Paris: Editions Odile Jacob, 1998)

—— 'Quelle place pour l'épigénétique?', Médecine/science, 21 (2005), pp. 367-69

Müller, Gerd B., 'Novelty and Key Innovation', in Encyclopedia of Evolution, ed. by M. Pagel (Oxford: Oxford University Press, 2002), pp. 827-30

Nijhout, H. Frederik, 'Metaphors and the Role of Genes in Development', BioEssays, 12.9 (1990), pp. 441-46 <https://doi.org/10.1002/bies.950120908>

Novas, Carlos and Nikolas Rose, 'Genetic Risk and the Birth of the Somatic Individual', Economy and Society, 29.4 (2000), pp. 485-513 <https://doi.org/10.1080/ 03085140050174750>

Oyama, Susan, The Ontogeny of Information: Developmental Systems and Evolution (Durham, NC: Duke University Press, 2000)

Pickersgill, Martyn, Jörg Niewöhner, Ruth Müller, Paul Martin, and Sarah Cunningham-Burley, 'Mapping the New Molecular Landscape: Social Dimensions of Epigenetics', New Genetics and Society, 32.4 (2013), pp. 429-47 <https:// doi.org/10.1080/14636778.2013. 861739>

Pigliucci, Massimo, 'Genotype-Phenotype Mapping and the End of the "Genes as Blueprint" Metaphor', Philosophical Transactions of the Royal Society B, 365 (2010), pp. 557-66 <https://doi.org/10.1098/rstb.2009.0241>

'What, If Anything, Is an Evolutionary Novelty?', Philosophy of Science, 75.5 (2008), pp. 887$98<$ https://doi.org/10.1086/594532>

Pigliucci, Massimo and Gerd B. Müller, Evolution: The Extended Synthesis (Cambridge, MA: MIT Press, 2010) <https://doi.org/10.7551/mitpress/9780262513678.001.0001>

Pinker, Steven, The Language Instinct (New York: William Morrow, 1994)

Quartz, Steven and Terrence J. Sejnowski, 'The Neural Basis of Cognitive Development: A Constructivist Manifesto', Behavioral and Brain Sciences, 20 (1997), pp. 537-96

Ramus, Franck, 'Genes, Brain, and Cognition: A Roadmap for the Cognitive Scientist', Cognition, 101 (2006), pp. 247-69

Reynaud, Valentine, 'Can Innateness Ascriptions Avoid Tautology?', Philosophia Scientiae, 18.3 (2014), pp. 177-90

Samuels, Richard, 'What Brains Won't Tell Us about the Mind: A Critique of the Neurobiological Argument against Representational Nativism', Mind \& Language, 13.4 (1998), pp. 54870

Sterelny, Kim and Paul E. Griffiths, Sex and Death: An Introduction to Philosophy of Biology (Chicago: University of Chicago Press, 1999) <https://doi.org/10.7208/chicago/ 9780226178653.001.0001> 
Waddington, Conrad H., 'Canalization of Development and the Inheritance of Acquired Characters', Nature, 150.3811 (1942), pp. 563-65

'The Epigenotype', Endeavour, 1 (1942), pp. 18-20

Weigel, Sigrid, 'An der Schwelle von Kultur und Natur. Epigenetik und Evolutionstheorie', in Evolution in Natur und Kultur, ed. by Volker Gerhardt and Julian Nida-Rümelin (Berlin: de Gruyter, 2010), pp. 103-23

West-Eberhard, Mary Jane, 'Phenotypic Accommodation: Adaptive Innovation Due to Developmental Plasticity', Journal of Experimental Zoology, 304b (2005), pp. 610-18

'Toward a Modern Revival of Darwin's Theory of Evolutionary Novelty', Philosophy of Science, 75.5 (2008), pp. 899-908 <https://doi.org/10.1086/594533> 